possibly influenced by the number of patients included. One subject associated Sjögren Syndrome, another one cutaneous Lupus and another patient, morphea. All of the patients included, received steroids and inmunosupressants. Azathioprine was the most frequently used (18/20), followed by Methotrexate (7/20), Rituximab (5/20), Mycophenolate (4/20), Cyclophosphamide (3/20) and Abatacept $(1 / 20)$.

Conclusions: In our cohort with AS, the most common clinical manifestation was ILD, and an important part of the patients showed a decreased DLCO. Capillaroscopy was pathogenic in most of them and could be useful for the diagnosis of AS, specially in those patients presenting solely with ILD at the clinical debut, although its pronostic value is still unknown. Multidisciplinary consultations are useful in the management of these truly challenging patients.

Disclosure of Interest: None declared

DOI: 10.1136/annrheumdis-2018-eular.4977

\section{AB1178 IS ANTI NUCLEAR ANTOBODY TEST REQUIRED CORRECTLY IN DAILY PRACTICE? A CHOOSING WISELY ANALYSIS}

D. Üsküdar Cansu' ${ }^{1}$, H. Üsküdar Teke ${ }^{2}$, E. Gündüz ${ }^{2}, \underline{\text { C. Korkmaz }}{ }^{1} .{ }^{1}$ Internal Medicine, Rheumatology; ${ }^{2}$ Internal Medicine, Hematology, Eskişehir Osmangazi University, Eskişehir, Turkey

Background: The most sensitive and gold-standard test used for the detection of antinuclear antibody (ANA) is accepted as the indirect immunofluorescence (IIF) test. ${ }^{1}$ International proposals, including the choice of rational examination, referred to as "choosing wisely", include significant efforts to reduce overuse of examinations such as the ANA. ${ }^{2}$

Objectives: Our aim was to retrospectively analyse the distribution of the ANA test samples for clinical reasons according to the clinical departments and to determine the most frequently requested reasons and to draw attention to the rational the ANA request.

Methods: Detection of ANA samples. Between January 2014 and August 2016, the results of the requested ANA test samples were screened for various reasons. The results of the first 4 divisions with the most common ANA test request and the reasons for the test were also analysed in detail (paediatric diseases were excluded). The ANA test was evaluated using the IIF method and the interpretation of the results was done according to the fluorescence intensity observed in the samples ( +1 positive,+2 positive,+3 positive and +4 positive).

Results: 11407 ANA samples were evaluated. The first 5 sections requiring ANA test most were as follows: Neurology 1917 (24.7\%), dermatology $1825(23.6 \%)$, rheumatology 1574 (20.3\%), paediatric nephrology 1404 (18.1\%) and haematology 1027 (13.3\%). In all the sections dealing with children, the ANA test number was 2461 and the mean age of the patients was 12.7 years, while the number of ANA samples required in the entire adult patient group was 8946 and the mean age of the patients was 46.8 years. ANA positivity rates for neurology, dermatology, rheumatology and haematology departments are 14.9\%, 15.4\%, 32.6\% and $14.1 \%$, respectively. The interclinical positivity rate was statistically significant $(p<0.0001)$. Positive $+1,+2,+3$ and +4 positivity rates were $33.5 \%, 27.8 \%, 22.2 \%$ and $16.3 \%$, respectively, when all positive ANA results were evaluated in terms of titre. When positivity was evaluated in terms of ANA positivity rates/titre, +4 posiitivity was found to be the most common in the patients from the rheumatology department $(135 / 262=51.5 \%)(p<0.0001)$.

The reasons for ANA requests were determined according to ICD diagnostic codes. According to this; in neurology, headache, cerebrovascular event and multiple sclerosis; in dermatology urticaria, psoriasis and dermatitis; in rheumatology, SLE, arthritis and fibromyalgia; in haematology, anaemia and thrombocytopenia were the most common reasons for ANA requests.

Conclusions: Based on specific recommendations and "choosing wisely", the ANA test should be requested in patients with a high pre-test probability for autoimmune diseases. Raising awareness in terms of wisely choosing ANA test is needed in departments outside the rheumatology.

\section{REFERENCES:}

[1] Meroni PL, Schur PH. ANA screening: an old test with new recommendations. Ann Rheum Dis. 2010;69:1420-2.

[2] Lesuis N, Hulscher ME, Piek E, Demirel H, van der Laan-Baalbergen N, Meek I, van Vollenhoven RF, den Broeder AA. Choosing Wisely in Daily Practice: An Intervention 3. Study on Antinuclear Antibody Testing by Rheumatologists. Arthritis Care Res (Hoboken). 2016;68:562-9.

Acknowledgements: None

Disclosure of Interest: None declared

DOI: 10.1136/annrheumdis-2018-eular.4168

\section{AB1179 \\ MUSCULOSKELETAL PATTERN OF 18F-FDG UPTAKE IN PATIENTS WITH POLYMYALGIA RHEUMATICA}

D. Prieto-Peña ${ }^{1}$, J. Loricera ${ }^{1}$, I. Martínez-Rodríguez ${ }^{2}$, J. Banzo ${ }^{2}$, M. CalderónGoercke $^{1}$, V. Calvo-Río ${ }^{1}$, C. González-Vela ${ }^{3}$, M. González-Gay ${ }^{1}$, J. Hernández ${ }^{4}$, R. Blanco ${ }^{1} .{ }^{1}$ Rheumatology; ${ }^{2}$ Nuclear Medicine; ${ }^{3}$ Pathology; ${ }^{4}$ Internal Medicine, Hospital Universitario Marqués de Valdecilla, IDIVAL, Santander, Spain

Background: Polymyalgia rheumatica (PMR) is a common inflammatory rheumatic disease of the elderly whose diagnosis is usually based on clinical and ultrasound findings. Recently, ${ }^{18}$ F-FDG PET/CT has been proposed as a promising one-step tool for assessing extent and severity of PMR. However, the pattern of ${ }^{18} \mathrm{~F}$-FDG uptake in PMR is not well established and there is a lack of imaging guidelines.

Objectives: Our aim was to describe the musculoskeletal pattern of ${ }^{18} \mathrm{~F}-\mathrm{FDG}$ uptake in PMR patients and assess if there were any differences between classic and atypical PMR.

Methods: Retrospective study of 75 patients with PMR and their respective PET/ CT scans from a referral centre. We considered two groups: a) Classic PMR: patients who fulfilled the 2012 EULAR/ACR criteria; and b) Atypical PMR: patients with symptoms resembling PMR but did not fulfil the 2012 EULAR/ACR criteria. Distributions of categorical variables were compared by Pearson Chi2 or Fisher exact test as appropriate.

Results: We evaluated 75 patients (27 men and 48 women) with a mean age \pm SD of $68.2 \pm 10.7$ years. A PET/CT was performed in all of them. Forty-two $(56 \%)$ patients classic PMR and $33(44 \%)$ atypical PMR. FDG-PET uptake was observed in the following musculoskeletal regions: in shoulders $(n=45)$, sternoclavicular joints $(n=33)$, hips $(n=32)$, cervical interspinous bursae $(n=8)$, lumbar interspinous bursae $(n=29)$, pubic symphysis $(n=4)$, subtrochanteric bursae $(n=20)$ ischial tuberosities $(n=19)$ and knees $(n=33)$. The comparative study between both groups is shown in the TABLE, without observing any statistical significance.

Abstract AB1179 - Table 1

\begin{tabular}{|l|l|l|l|l|}
\hline & $\begin{array}{l}\text { PMR } \\
(\mathrm{N}=75)\end{array}$ & $\begin{array}{l}\text { llassic PMR } \\
(\mathrm{n}=42)\end{array}$ & $\begin{array}{l}\text { Atypical PMR } \\
(\mathrm{n}=33)\end{array}$ & $\mathrm{P} \#$ \\
\hline Sex (women), $n(\%)$ & $48(64.0)$ & $29(69.0)$ & $19(57.6)$ & 0.30 \\
\hline Age (years), mean \pm SD & $68.2 \pm 10.7$ & $73.9 \pm 8.5$ & $61.6 \pm 9.5$ & 0.60 \\
\hline F-FDG uptake & & $25(59.5)$ & $20(60.6)$ & 0.92 \\
\hline Shoulders & $45(60.0)$ & $20(47.6)$ & $13(39.4)$ & 0.48 \\
\hline Sternoclavicular joints & $33(44.0)$ & $19(45.2)$ & $13(39.4)$ & 0.76 \\
\hline Hips & $32(43.7)$ & $5(12.0)$ & $3(9.0)$ & 0.98 \\
\hline Cervical interspinous bursae & $8(10.7)$ & $12(28.6)$ & $11(33.3)$ & 0.40 \\
\hline Lumbar interspinous bursae & $29(38.6)$ & $1(2.4)$ & $3(9.1)$ & 0.31 \\
\hline Pubic symphysis & $4(5.3)$ & $12(28.6)$ & $8(24.3)$ & 0.67 \\
\hline Subtrochanteric bursae & $20(26.7)$ & $12(28.6)$ & $7(21.3)$ & 0.47 \\
\hline Ischial tuberosities & $19(25.4)$ & $16(38.1)$ & $17(51.5)$ & 0.25 \\
\hline Knees & $33(44.0)$ & $25(59.5)$ & $20(60.6)$ & 0.92 \\
\hline
\end{tabular}

\# Comparisons between classic and atypical PMR.

Conclusions: In patients with PMR, ${ }^{18} \mathrm{~F}-\mathrm{FDG}$ uptake seems to be more frequent in shoulders, sternoclavicular joints, hips and knees. In addition, ${ }^{18} \mathrm{FDG}$ uptake can be also detected in lumbar interspinous bursae and less frequently in subtrochanteric bursae, ischial tuberosities, cervical interspinous bursae and pubic symphysis. No differences between classic and atypical PMR patients were seen. Disclosure of Interest: None declared

DOI: 10.1136/annrheumdis-2018-eular.4961

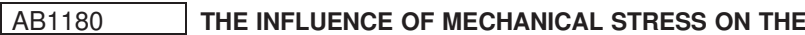 HANDS ON ULTRASOUND RESULTS: A PROSPECTIVE STUDY WITH VOLLEYBALL PLAYERS (US-VOLLEY) - PRELIMINARY DATA}

D. Scheicht ${ }^{1}$, S. Zeglam ${ }^{1}$, S. Frechen ${ }^{2}$, J. Strunk ${ }^{1} .{ }^{1}$ Klinik für Rheumatologie, Krankenhaus Porz am Rhein; ${ }^{2}$ Independent researcher, Köln, Germany

Background: Various imaging studies have found an influence of physical exercise on joint and tendon pathology in ultrasound. It is not clear ${ }^{1}$ how specific grey scale and power Doppler changes are in a context of mechanical stress and ${ }^{2}$ if a distinction to findings in acute arthritis exists.

Objectives: To examine via grey scale and power Doppler ultrasound the acute physiological effects of increased physical stress on the fingers and wrists and their surrounding structures through volleyball training in amateur healthy subjects as a reference to the known pathological findings (effusion, increased perfusion) in acute arthritis.

Methods: Examination of 18 healthy amateur volleyball players via musculoskeletal ultrasound before and directly after their routine volleyball practice. Ultrasound assessment included a grey scale and power Doppler examination of the dominant hand (longitudinal planes of the dorsal wrist and dorsal and palmar 